\title{
Lethal Firearm-Related Violence Against Canadian Women: Did Tightening Gun Laws Have an Impact on Women's Health and Safety?
}

\author{
Samara McPhedran, PhD \\ International Coalition for Women in Shooting and Hunting, \\ New South Wales, Australia
}

Gary Mauser, PhD

Simon Fraser University

\begin{abstract}
Domestic violence remains a significant public health issue around the world, and policy makers continually strive to implement effective legislative frameworks to reduce lethal violence against women. This article examines whether the 1995 Firearms Act (Bill C-68) had a significant impact on female firearm homicide victimization rates in Canada. Time series of gender-disaggregated data from 1974 to 2009 were examined. Two different analytic approaches were used: the autoregressive integrated moving average (ARIMA) modelling and the Zivot-Andrews (ZA) structural breakpoint tests. There was little evidence to suggest that increased firearms legislation in Canada had a significant impact on preexisting trends in lethal firearm violence against women. These results do not support the view that increasing firearms legislation is associated with a reduced incidence of firearm-related female domestic homicide victimization.
\end{abstract}

Keywords: violence; women; firearms; domestic; intimate partner

$\mathrm{I}$ $\mathrm{n}$ recognition of domestic violence as a significant public health issue, and as a signatory to the Optional Protocol to the United Nations (UN) Convention on the Elimination of All Forms of Discrimination Against Women, Canada has committed increasing time and effort to enhancing the safety framework around women and children, particularly regarding protection from domestic violence (United Nations Department of Economic and Social Affairs [UN DESA], 2011). Although men are more likely than women to become victims of violence, women are more likely to experience violence from current or former intimate partners (Beattie \& Cotter, 2010). Male homicide victims (who represent most homicide victims in Canada; around $65 \%$ to $76 \%$ of all homicides between 1999 and 2009) are generally killed by a friend or acquaintance, whereas Canadian women are more likely to be killed by a current or a former partner (Beattie \& Cotter, 2010). Although the prevalence of domestic violence is difficult to accurately quantify, in 2009, 
an estimated $6 \%$ of Canadians with a current or former spouse reported being physically and/or sexually abused by their spouse in the preceding 5 years. A higher number-17\%reported some form of emotional or financial abuse in their current or former relationship.

At the most extreme end of the spectrum of violent and abusive behaviors between 2000 and 2009, there were 738 spousal homicides in Canada, with the rate of female victimization around three times greater than the male rate of victimization (Beattie \& Cotter, 2010). Also, there are gender differences in the severity of abuse experienced; women are likely to experience severe and chronic patterns of violence and controlling behavior, involving high levels of fear and injury, which men are unlikely to experience (Ansara \& Hindin, 2010). Although there have been long-term, ongoing downward trends in domestic homicide (and, indeed, homicide overall) since the 1970s (Beattie \& Cotter, 2010), reducing the incidence of lethal violence against women remains an important goal for public policy. This highlights the importance of developing a robust base of evidence on which policy can be based.

In terms of lethal violence prevention, firearms - although used relatively infrequently in domestic homicides in Canada-have received particular attention within public debate regarding violence against women (Cockburn, 2011). It has been suggested during parliamentary hearings, for instance, that increased legislation around the private ownership of firearms may have benefits for reducing violence against women, through a combination of controlling access, increasing penalties for inappropriate use of firearms, and reducing overall levels of legal firearms ownership (Senior, 2010). However, it has also been argued that restricting a particular method of enacting violence does not address the causal factors underlying violence, that method substitution may occur, and that levels of legal firearms ownership are unrelated to levels of domestic homicide (Kates \& Mauser, 2007; Kovandzic, Schaffer, \& Kleck, 2005; Mauser, 2007).

These divergent opinions about the role of firearms legislation in the context of domestic homicide evoke the long-standing, broader debate about the efficacy or otherwise of method restriction as a public health and violence prevention measure. However, although there is a considerable body of research into method restriction as a violence prevention strategy in the United States (for comprehensive meta-analysis, see Makarios \& Pratt, 2012), empirical evidence about the efficacy of method restriction in reducing firearm homicides in Canada - a country that has progressively tightened its firearms legislation over a period of decades-is equivocal.

Although some studies have observed ongoing declines in Canadian firearm homicide (e.g., Mauser, 2007; McPhedran, Baker, \& Singh, 2011), it is unclear whether the ongoing declines can be attributed to legislative change (Mauser, 2007; Stenning, 2003). Although various studies report a significant change in firearm homicide trends after legislative changes (Blais \& Gagné, 2011; Bridges, 2004; Department of Justice, 1996; Sproule \& Kennett, 1988), others have found no effect (Langmann, 2012; Mauser \& Holmes, 1992; Mundt, 1990; Stenning, 2003). These results are similar to international findings, particularly for countries with comparable social histories and social circumstances to Canada (such as the United Kingdom and Australia; see Baker \& McPhedran, 2007; Lee \& Suardi, 2010; McPhedran et al., 2011).

Despite considerable public and media debate of the potential role of firearms legislation in reducing or preventing lethal violence, and successive epochs of legislative change (see Table 1 for an overview of key changes), there have been few empirical studies to test whether tightening firearms legislation has had an impact on firearm-related lethal violence against women. Most research has focused on legislative changes that occurred in the late 1970s through to the early 1990s, rather than the most recent (and, arguably, most stringent) raft of reforms. 
TABLE 1. Overview of Recent Canadian Firearms Legislation

\begin{tabular}{|c|c|c|}
\hline Bill & Assent Date & Key Changes \\
\hline$C-51$ & 1977 & $\begin{array}{l}\text { - Firearms Acquisition Certificate (FAC) introduced } \\
\text { - Ban on fully automatic firearms } \\
\text { - Penalty for "unsafe storage" of firearms } \\
\text { - Additional penalties for use of a firearm in the course } \\
\text { of another crime }\end{array}$ \\
\hline $\mathrm{C}-17$ & 1991 & $\begin{array}{l}\text { - Photo required for FAC } \\
\text { - Mandatory safety tests for FAC } \\
\text { - } 28 \text {-day waiting period } \\
\text { - Registration of semiautomatic military-style firearms } \\
\text { - Ban on high-capacity magazines }\end{array}$ \\
\hline C-68 & 1995 & $\begin{array}{l}\text { - Firearm owners required to be licensed }{ }^{a} \\
\text { - All long guns (rifles and shotguns) required to be registered } \\
\text { - Bans on various handguns and "paramilitary" firearms } \\
\text { - Mandatory minimum sentences for firearm crimes }\end{array}$ \\
\hline
\end{tabular}

${ }^{\mathrm{a} C h a n g e s ~ w e r e ~ n o t ~ f u l l y ~ i m p l e m e n t e d ~ u n t i l ~ t h e ~ e n d ~ o f ~} 1998$.

Also, studies in this area characteristically use statistical methods that assume an impact of legislation at a particular time (for instance, by comparing homicide rates before and after a certain year), rather than analytical methods that avoid assumptions about impacts occurring at a certain time. Imposing an artificial "breakpoint" in a data series may limit the detection of policy change impacts. In addition, the studies cited earlier typically examine either domestic firearm homicide victimization overall or female firearm homicide victimization overall rather than adopting a gender-disaggregated approach to domestic firearm homicide.

This article begins to redress current shortcomings in knowledge. Specifically, it uses two different statistical methods to examine whether there is empirical evidence linking increased gun laws in Canada with changes in female homicide victimization, with particular emphasis on the 1995 legislative reforms and lethal firearm violence between current and former intimate partners.

\section{METHODS}

\section{Data Source}

Custom Homicide Survey data tables from Statistics Canada were used in conjunction with published data from the Department of Justice, Canada. Time series of genderdisaggregated data from 1974 to 2009 were examined. The series were the number of firearm homicides and the number of spousal firearm homicides (i.e., firearm homicides occurring between current and former intimate partners; for males, this was extremely 
TABLE 2. ARIMA Model Parameters

\begin{tabular}{lcrrr}
\hline & Model & AIC & BIC & $R^{2}$ \\
\hline Firearm homicide (male) & $2,1,1$ & 12.5 & 8.4 & 0.6 \\
Firearm homicide (female) & $1,1,3$ & 32.1 & 26.9 & 0.5 \\
Firearm homicide_domestic (female) & $1,1,3$ & 60.9 & 55.7 & 0.4 \\
\hline
\end{tabular}

Note. AIC $=$ Akaike information criteria; $\mathrm{BIC}=$ Bayesian information criteria.

low hence excluded from detailed statistical analysis). Spousal homicide was defined by Statistics Canada as homicide involving legally married, common-law, separated, and divorced persons age 15 years or older. The number of homicides was converted to a rate per 100,000 population, by gender, using Statistics Canada population data.

Two different analytic approaches were used: autoregressive integrated moving average (ARIMA) modelling, and Zivot-Andrews (ZA) structural breakpoint tests. These methods have been used on similar homicide time series data (Baker \& McPhedran, 2007; Langmann, 2012; Lee \& Suardi, 2010; McPhedran et al., 2011).

Best-fit ARIMA models were selected from examination of Akaike Information Criteria (AIC) and Bayesian Information Criteria (BIC), in conjunction with model fit statistics, and with the stipulations that all resulting predictions be positive values and that the model be both stable and invertible. Table 2 provides the models used for each time series. Models were applied to the time series to 1995, switching to dynamic (out of sample) predictions from 1996 onward. The ARIMA model allows future values of the time series to be estimated by a linear combination of past values and a series of errors, and uses a maximum likelihood fit of the specified ARIMA model to the time series. This provided the opportunity to describe and predict the evolution of the time series to the year 2009. Predicted and actual rates of lethal violence were compared for each post-1995 time series, using $t$ tests.

The ARIMA method used herein sets an artificial breakpoint in the data, corresponding with the passage of Bill C-68 in 1995. In contrast, ZA tests do not presuppose a break in the data. Rather, this method detects the presence of a breakpoint in the data at any point in time rather than assuming the presence of a breakpoint at a "known" point (Zivot \& Andrews, 1992). This is particularly useful in the current setting because different elements of the 1995 legislation were implemented at different times. In addition to identifying an endogenous structural break, the ZA test overcomes the difficulty identified by Perron (1989); namely, that in failing to account for a structural break, conventional unit root tests (such as the Augmented Dickey-Fuller [ADF] test) may lead to the incorrect conclusion that the data contain a unit root, when the series is instead stationary around a structural break in the intercept (or "level" of a time series) and/or trend (or "rate of growth" of a time series).

\section{RESULTS}

Figure 1 shows rates over time for each homicide time series. The highest rate of firearm homicide occurred among males. Note that the rate of male domestic firearm homicide victimization was very low (typically less than five cases per year) and not amenable to meaningful analysis. It is shown here for illustrative purposes only. 


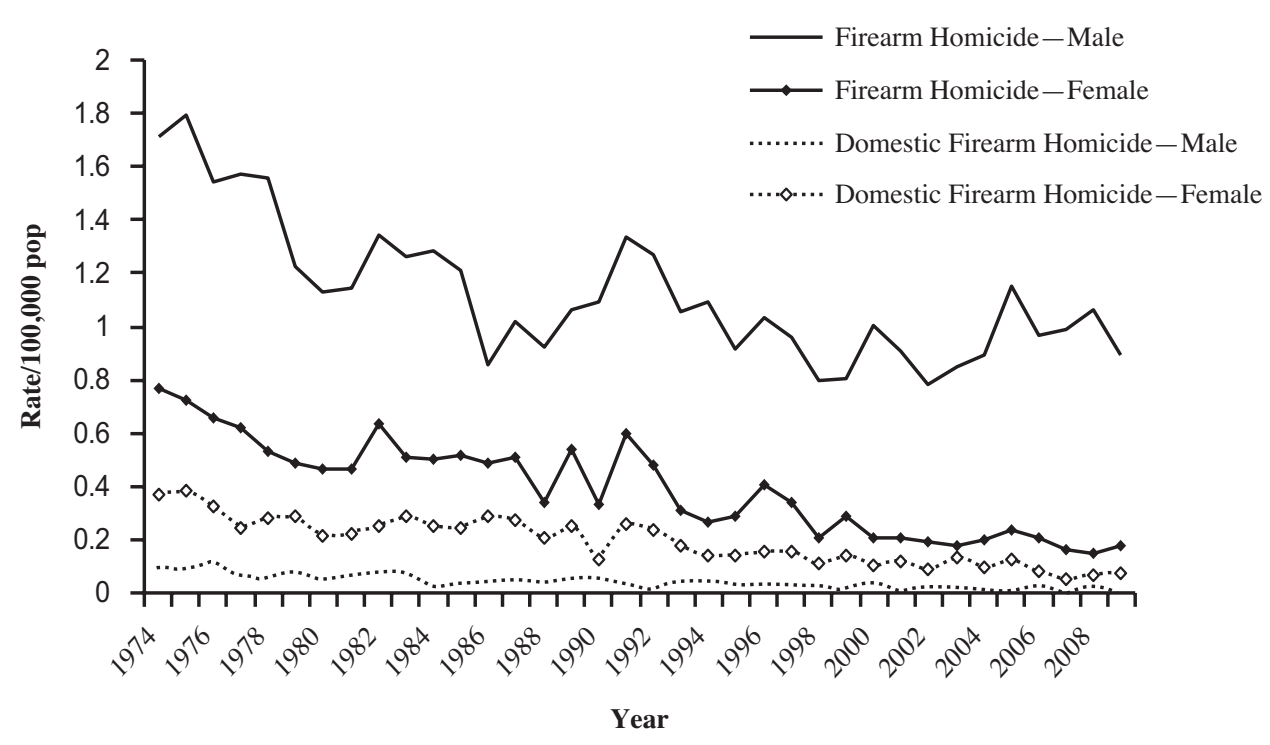

Figure 1. Rate of firearm homicide 1974 to 2009: overall and domestic.

\section{ARIMA Modelling}

Predicted and observed rates of firearm homicide for males, after 1995, differed significantly (mean predicted $=0.67$, mean observed $=0.93 ; t=5.072, p<.05$ ). These results suggest that, when 1995 is used as a predetermined breakpoint in the time series for male firearm homicide rates, the actual decline in firearm homicides was slower than what would have been expected had the historical trends continued at the same rate after 1995 as before. This finding does not support the expectation that tightening legislation would lead to more rapid declines in firearm homicide.

In contrast, the observed rate of firearm homicide among females post-1995 did not differ significantly from the predicted rate (mean predicted $=0.21$, mean observed $=0.23$; $t=1.53, p>.05$ ). For domestic firearm homicides, actual and predicted death rates for females did not differ significantly (mean predicted $=0.11$, mean observed $=0.11$; $t=0.28, p>.05$ ). These results imply that the preexisting downward trends in female victimization for both firearm homicides in general, and spousal firearm homicides specifically, were not affected by the legislative changes; if there had been an impact, then predicted rates would be expected to be significantly higher than actual rates.

\section{Zivot-Andrews Tests}

Table 3 summarizes ZA test results for each gender-disaggregated time series, indicating years in which a significant breakpoint was found (or, alternatively, denoting statistical nonsignificance where applicable). For males, there were no significant breaks found in the firearm homicide time series. For female firearm homicide, and female domestic firearm homicide, significant breaks were found. However, none of the breaks in female domestic firearm homicide victimization corresponded with the passage and implementation of the 1995 legislative changes (or, indeed, the earlier Bill C-17); in all cases, the structural breaks occurred before those changes took place. 
TABLE 3. Zivot-Andrews Structural Breakpoint Test Results

\begin{tabular}{llccc}
\hline & & $\begin{array}{c}\text { Breakpoint } \\
\text { (intercept and trend) }\end{array}$ & $\begin{array}{c}\text { Breakpoint } \\
\text { (trend only) }\end{array}$ & $\begin{array}{c}\text { Breakpoint } \\
\text { (intercept only) }\end{array}$ \\
\hline Firearm homicide & Male & NS & NS & NS \\
& Female & $1982^{* *}$ & $1979^{* *}$ & $1993^{* *}$ \\
$\begin{array}{l}\text { Firearm homicide- } \\
\text { domestic }\end{array}$ & Female & $1982^{* *}$ & $1978^{* *}$ & $1983^{* *}$ \\
\hline
\end{tabular}

Note. $\mathrm{NS}=$ no statistically significant break.

*Significant at $p<.05$. ** Significant at $p<.01$.

\section{DISCUSSION}

Using two different time series analysis methods, little evidence was found to suggest that increased firearms legislation in Canada in recent years had a significant impact on preexisting trends in lethal firearm violence against women, either overall or within intimate relationships. The current results suggest that hypothesized links between the Canadian firearms legislation of 1995 and reductions in lethal violence against women (Senior, 2010) are not well supported by empirical evidence. This is consistent with observations made by Langmann (2012) and extends those observations by applying gender disaggregation to the data.

If a relationship between firearms legislation and declines in domestic firearm homicide were inferred from the current results, it appears that Bill C-51 in 1977 may be the only legislative change potentially associated with changes in the occurrence of firearm-related domestic homicide. Recognizing that past behavior is a strong predictor of future behavior, that Bill introduced the requirement that a basic criminal background check (including any history of interpersonal/domestic violence) must be conducted for prospective firearms owners - thus, theoretically, limiting legal access to firearms by persons with a documented history of violence. This seemingly flags the importance of initiatives to detect and prosecute perpetrators of domestic violence to ensure that they are not able to legally access firearms.

\section{IMPLICATIONS FOR PRACTICE AND POLICY}

These findings have important implications for policy development in the area of women's health and safety. The apparent limitations of a method restriction approach (in the form of stringent firearms legislation) to reducing lethal violence against women highlights the need to explore early intervention strategies such as assisting women to leave violent relationships and become economically independent, coupled with proactive policing, risk assessment, and strengthened legal penalties for domestic violence (e.g., Browne, 1993; Langan, 1986; Trujillo \& Ross, 2008). In addition, there is demonstrated value in programs focusing on specialized, "wrap around" legal, advocacy, accommodation, and counselling services (e.g., Barner \& Carney, 2011; Bell, Perez, Goodman, \& Dutton, 2011; Goodman \& Epstein, 2005; Hague \& Rowe, 2008). To inform policymaking, it may also 
be useful to longitudinally quantify whether or not the risk assessment techniques (which typically include questions about firearms access) that are increasingly used to assist domestic violence victims in making decisions about their own safety (Bowen, 2011; Grant \& Rowe, 2011) have any impact on the incidence of intimate partner homicide.

It should be noted that firearm homicides among men do not appear to have been significantly impacted by legislative change. Given that men represent most homicide victims in Canada (both firearm and non-firearm homicide), the current results suggest that a method restriction approach to violence prevention is unlikely to be sufficient to reduce male firearm homicide victimization and that a more comprehensive set of prevention strategies is required. For example, it has been found that Canadian firearm homicides, although rare, occur disproportionately in urban crime "hotspots" (Royal Canadian Mounted Police, 2006). Relationships between the illicit drug trade and firearm homicide have also been found, and recent spikes in the rate of Canadian firearm homicide have been linked with gang- and drug-related activity involving men from socially disadvantaged backgrounds (Royal Canadian Mounted Police, 2006).

It is reasonable to speculate that, in relation to males from disadvantaged demographic groups and males who are involved with criminal behaviors such as illicit drug activity, there may also be overlap with firearm misuse in the context of intimate partner violence. However, a limitation of this study was that there were no available data about the legal status of firearms used in domestic homicide, or about the characteristics of homicide offenders (such as a history of perpetrating domestic violence, or involvement with other forms of criminal behavior). Although Statistics Canada Homicide data do include a variable about whether police were aware of a history of domestic violence, this variable is not sufficiently detailed to answer such questions. In addition, multivariate analyses were not performed, meaning that the possible influence of social and economic variables on observed firearm homicide rates could not be taken into account. This would be an important future direction, given that past research has suggested downward trends in intimate partner homicide are associated with wider social changes such as divorce rates, employment, education, improved resources to address domestic violence, and women's improved economic status (e.g., Dawson, Bunge, \& Balde, 2009; Dugan, Nagin, \& Rosenfeld, 1999, 2003).

Although it is known that most Canadian firearm homicides involve unlicensed offenders (i.e., illegal ownership — see for example Dauvergne \& De Socio, 2008), it would be helpful to obtain domestic-homicide specific data. From a policy perspective, this information could provide useful insights about potential relationships between illegal firearms ownership, other illicit activities, and domestic (and other) violence. This may in turn inform the development of more targeted intervention strategies to identify and assist women in especially "high-risk" violent relationships before those women become homicide victims.

The purpose of this study was not to examine non-firearm homicides (either overall or domestic). However, it would be beneficial to examine non-firearm homicides to gain a more comprehensive picture of homicide overall and to assess the possible presence of method substitution from firearms to other weapons. It is possible that structural breaks in non-firearm homicide may have occurred around the 1995 firearms legislative changes, which could suggest some degree of displacement from firearms to other methods. It has been noted, for instance, that homicides involving stabbing have increased (Beattie \& Cotter, 2010), and investigation of when this trend began may prove informative. Work is currently underway to address this question. 


\section{REFERENCES}

Ansara, D. L., \& Hindin, M. J. (2010). Exploring gender differences in the patterns of intimate partner violence in Canada: A latent class approach. Journal of Epidemiology and Community Health, 64(10), 849-854.

Baker, J., \& McPhedran, S. (2007). Gun laws and sudden death: Did the Australian firearms legislation of 1996 make a difference? British Journal of Criminology, 47, 455-469.

Barner, J. R., \& Carney, M. M. (2011). Interventions for intimate partner violence: A historical review. Journal of Family Violence, 26, 235-244.

Beattie, S., \& Cotter, A. (2010). Homicide in Canada 2009. Juristat, 30, no. 3. Ontario: Statistics Canada.

Bell, M. E., Perez, S., Goodman, L., \& Dutton, M. A. (2011). Battered women's perceptions of civil and criminal court helpfulness: The role of court outcomes and process. Violence Against Women, 17(1), 71-88.

Blais, E., \& Gagné, M. (2011). L'effet des lois en matière de contrôle des armes à feu sur les homicides au Canada, 1974-2004. Canadian Journal of Criminology and Criminal Justice, 53(1), 27-62.

Bowen, E. (2011). An overview of partner violence risk assessment and the potential role of female victim risk appraisals. Aggression and Violent Behaviour, 16, 214-226.

Bridges, F. S. (2004). Gun control law (Bill C-17), suicide and homicide in Canada. Psychological Reports, 94, 819-826.

Browne, A. (1993). Violence against women by male partners: Prevalence, outcomes and policy implications. American Psychologist, 48(10), 1077-1087.

Cockburn, C. (2011). Guns, war and the domestic battlefield. Retrieved from http://www.open democracy.net/5050/cynthia-cockburn/guns-war-and-domestic-battlefield

Dauvergne, M., \& De Socio, L. (2008). Firearms and violent crime. Juristat, 28(2), 1-14.

Dawson, M., Bunge, V., \& Balde, T. (2009). National Trends in Intimate Partner Homicides: Explaining Declines in Canada, 1976 to 2001. Violence Against Women, 15(3), 276-306.

Department of Justice. (1996). A statistical analysis of the impacts of the 1977 firearms control legislation. Ontario, Canada: Queens Printer.

Dugan, L., Nagin, D. S., \& Rosenfeld, R. (1999). Explaining the decline in intimate partner homicide: The effects of changing domesticity, women's status, and domestic violence resources. Homicide Studies, 3(3), 187-214.

Dugan, L., Nagin, D. S., \& Rosenfeld, R. (2003). Exposure reduction or retaliation? The effects of domestic violence resources on intimate-partner homicide. Law and Society Review, 37(1), 169-198.

Goodman, L., \& Epstein, D. (2005). Refocusing on women: A new direction for policy and research on intimate partner violence. Journal of Interpersonal Violence, 20(4), 479-487.

Grant, S., \& Rowe, M. (2011). Running the risk: Police officer discretion and family violence in New Zealand. Policing and Society, 21(1), 49-66.

Hague, G., \& Rowe, S. (2008). Inching forward on domestic violence: The "coordinated community response' and putting it into practice in Cheshire. Journal of Gender Studies, 17(3), 185-199.

Kates, D. B., \& Mauser, G. (2007). Would banning firearms reduce murder and suicide? A review of international and some domestic violence. Harvard Journal of Law and Public Policy, 30(2), 650-694.

Kovandzic, T., Schaffer, M. E., \& Kleck, G. (2005). Gun prevalence, homicide rates and causality: A GMM approach to endogeneity bias. London, United Kingdom: Centre for Economic Policy Research.

Langan, P. (1986). Preventing violence against women. Washington, DC: Bureau of Justice Statistics. Langmann, C. (2012). Canadian firearms legislation and effects on homicide 1974 to 2008. Journal of Interpersonal Violence, 27(12), 2303-2321. http://dx.doi.org/10.1177/0886260511433515 
Lee, W.-S., \& Suardi, S. (2010). The Australian firearms buyback and its effect on gun deaths. Contemporary Economic Policy, 28(1), 65-79.

Makarios, M. D., \& Pratt, T. C. (2012). The effectiveness of policies and programs that attempt to reduce firearm violence: A meta-analysis. Crime and Delinquency, 58(2), 222-244.

Mauser, G. (2007). Hubris in the North: The Canadian Firearms Registry. Vancouver, Canada: The Fraser Institute.

Mauser, G., \& Holmes, R. (1992). An evaluation of the 1977 Canadian Firearms Legislation. Evaluation Review, 16, 603-617.

McPhedran, S., Baker, J., \& Singh, P .(2011). Firearm homicide in Australia, Canada, and New Zealand: What can we learn from long-term international comparisons? Journal of Interpersonal Violence, 26(2), 348-359.

Mundt, R. J. (1990). Gun control and rates of firearms violence in Canada and the United States. Canadian Journal of Criminology, 32, 137-154.

Perron, P. (1989). The great crash, the oil price shock and the unit root hypothesis. Econometrica, $57,1361-1401$.

Royal Canadian Mounted Police. (2006). Feature focus: Youth gangs and guns. Ottawa, Canada: Author.

Senior, P. (2010). May 4 Testimony to the Standing Committee on Public Safety and National Security. Ontario, Canada: House of Commons.

Sproule, C. F., \& Kennett, D. J. (1988). The use of firearms in Canadian homicides 1972-1982. Canadian Journal of Criminology, 30, 31-37.

Stenning, P. C. (2003). Long gun registration: A poorly aimed longshot. Canadian Journal of Criminology and Criminal Justice, 45(4), 479-488.

Trujillo, M. P., \& Ross, S. (2008). Police responses to domestic violence: Making decisions about risk and risk management. Journal of Interpersonal Violence, 23(4), 454-473.

United Nations Department of Economic and Social Affairs. (2011). Convention on the elimination of all forms of discrimination against women. Retrieved from http://www.un.org/womenwatch/ daw/cedaw/

Zivot, E., \& Andrews, D. (1992). Further evidence on the great crash, the oil price shock, and the unit root hypothesis. Journal of Business and Economic Statistics, 10, 251-270.

Correspondence regarding this article should be directed to Samara McPhedran, $\mathrm{PhD}$, International Coalition for Women in Shooting and Hunting (WiSH), PO Box 393, Glebe, New South Wales, Australia, 2037. E-mail: chair@ic-wish.org 